\title{
Progressive decline of semantic memory with preservation of number processing and calculation
}

\author{
H.F.A. Diesfeldt \\ Stichting Verpleeghuiszorg Nederland, Department of Psychogeriatrics, Naarderstraat 81, \\ 1251 BG Laren, The Netherlands
}

\begin{abstract}
A 75-year-old man with seven years of formal education displayed a syndrome of progressive and severe lexical impairments to word comprehension and production (semantic dementia). While he lost the ability to recognize written arithmetical signs, he could still retrieve the arithmetical facts for addition and subtraction of all number combinations of 1 to 9 and 11 to 19 , though his mastery of multiplication tables ( 2 to 9) was unreliable. Calculation procedures were intact. Over the course of 18 months the components of the calculation system dissolved selectively: arithmetical procedures and number reading were spared, despite increasing damage to the arithmetic fact store. He retained the ability to read the time on analogue clocks. Selective preservation of components of the calculation system in the context of severe language deficits and dementia, supports the independent status of numerical abilities. The dissociation between intact arithmetical procedures and impaired table fact retrieval was paralleled by a dissociation between preserved procedures of phonology and syntax of language and impaired retrieval of content words, suggesting that the core deficit was a degradation of the central semantic store of learned knowledge of both words and arithmetic table facts.
\end{abstract}

Keywords: Cognitive neuropsychology - Mathematical abilities - Semantic dementia

\section{INTRODUCTION}

There is a growing interest in patients with degenerative brain disease whose illness results in an intricate pattern of selective impairments and preserved abilities. Patients have been described with predominant deficits in areas other than mnestic abilities (Neary et al., 1988; Schwartz, 1990; Freedman et al., 1991; Hodges et al., 1992). The diversity of the cognitive deficits in individual patients demonstrates the non-homogeneous nature of dementia and the selective vulnerability of subsystems of the brain. Brain lesions that are presumed to be diffuse may still cause selective damage to the cognitive system. The resulting dissociations between impaired and preserved functions are important since they show how the cognitive system can fractionate into multiple distinct informationprocessing modules (Shallice, 1988).

This report describes a patient who became severely demented after a course of progressive impairments of word finding and language comprehension, whereas his abilities of calculation and number processing remained intact. His growing impairment to verbal and non-verbal semantic knowledge has been described elsewhere (Diesfeldt, 1992). The purpose of the present article is to describe and explain the selective dissolution, later in the course of his illness, of the mathematical abilities of this patient.

\section{CASE PRESENTATION}

This 75-year-old, right-handed receptionist, with 7 years of formal education, had a 5-year history of increasing difficulty in remembering common words and names of relatives and friends. Spontaneous speech was fluent with normal syntax, phonology and prosody, but severe wordfinding problems were apparent including many circumlocutions and semantic paraphasias. For example, he once asked his wife to bring "lemonade for shaving the wall", while he in fact intended to paint the garden fence. At home, he exhibited problems identifying tools and household objects. Orientation to place and time was normal. He showed $100 \%$ correct recognition of five pictures after a delay of $10 \mathrm{~min}$ on a four-alternative, forced-choice recognition task. He could also easily retrieve three hidden objects after a delay of $75 \mathrm{~min}$. His autobiographical and everyday memory was good: he remembered appointments, recent family events and visits to the hospital. His performances on several language and visuospatial tasks are summarized in Table I.

He perfectly read prose passages and several lists of words, including non-words, but he made phonologically plausible regularization errors to familiar words with irregular spelling-to-sound correspondence (surface dyslexia). Writing was normal in the mechanical sense (orthography) but showed spelling errors, especially for 
TABLE I. Summary of performances on language and other cognitive tasks on two occasions, 18 months apart, showing severe deficits of naming and comprehension (except for syntax and function words), mildly impaired repetition, but normal digit span, and intact visuospatial skills

\begin{tabular}{lrr}
\hline Task (maximum score) & Test & Retest \\
\hline Spontaneous speech (words/4 min) & 608 & 6181 \\
Picture naming (18) & 0 & 0 \\
$\quad$ Semantic paraphasias & 6 & 1 \\
Phonemic paraphasias & 1 & 0 \\
Neologisms & 0 & 4 \\
Stereotypes & 3 & 13 \\
Omissions & 8 & 0 \\
Category fluency (animals) & 0 & 0 \\
Comprehension & & \\
Nouns (18) & 11 & 4 \\
Syntax (45) & 40 & 31 \\
Function words (37) & 36 & 37 \\
Repetition AAT (150) & 129 & 113 \\
Digit span forward & 7 & 5 \\
Digit span backward & 5 & 0 \\
Visuospatial skills & & \\
Raven CPM (36) & 28 & 26 \\
Clock reading (18) & 18 & 18 \\
Rey figure copy (35) & 35 & 35 \\
WAIS block design: complete patterns (13) & 6 & 8 \\
\hline
\end{tabular}

${ }^{1 E x t r a p o l a t i o n ~ b a s e d ~ o n ~} 2$ min speech sample.

2For example, "bus" for orange, chair, toadstool, windmill, glasses; "woman" for squirrel, horse.

irregular words, and the same disorders of semantic content as his spontaneous speech.

A full medical investigation did not disclose any illness that could explain his impairments. A CT scan showed moderate generalized atrophy with enlarged ventricles and sulci, particularly in the left perisylvian area.

On follow-up over the subsequent 18 months, his linguistic abilities deteriorated, but not his visuospatial skills. At age 77 he was admitted to a nursing home, where he died, 3 years later, in a state of very severe dementia. Autopsy was not undertaken.

\section{EXPERIMENTAL INVESTIGATIONS}

The experimental investigation of the patient's numerical skills was derived from a theoretically well motivated model that distinguishes four subdomains of numerical competence: number processing, comprehension of operational symbols, arithmetic fact retrieval, and execution of calculation procedures (McCloskey et al., 1991; Macaruso et al., 1992; Geary, 1993). Six healthy male volunteers served as controls. Their ages ranged from 68 to 83 (median $=77$ ) and they were of similar educational attainment to the patient.

\section{Number processing: reading and writing}

Even at a stage of very impaired language (see retest results in Table I) the patient made only one error in reading a list of 68 Arabic numbers, including 18 complex numbers containing four to six digits (e.g. 50914 , $907869)$. He thus demonstrated preserved lexical and syntactic number transcoding processes. The control subjects erred in zero to four numbers.

While initial tests of writing numbers to spoken verbal stimuli uncovered no impairments, he appeared to be very deficient in writing such numbers at the follow-up stage of this investigation. Whereas the normal control subjects made no errors, the patient confused verbal and digital codes (e.g. writing 20 as "twenty", 14 as "F-T", and 18 as " 8 -T") and failed to lexicalize composed numeral words as whole numbers (e.g. writing 13 as "3-10"). He had no difficulty copying written numbers.

\section{Comprehension of operational symbols}

He did not understand the visual symbols for the operational signs $(+,-, \times$, or $\div)$. However, he understood the spoken words for multiplication and division, such as "times" and "divided by". His understanding of the spoken operational terms for addition ("plus") and subtraction ("minus") was variable. Oral additions and subtractions could be explained by giving some examples of the procedures, using descriptive terms such as "7 add 4", or "14 subtract $11 "$.

\section{Arithmetic fact retrieval}

Simple problems of addition, subtraction and multiplication were given in the written and auditory modalities simultaneously. They were blocked by operation. Within blocks, digit pairs were presented in random order. His oral responses were recorded on tape. Addition and subtraction were tested for all combinations of numbers between 1 and 9 and those between 11 and 19, except for calculations with zero or negative numbers as the remainder. Knowledge of multiplication tables was tested with all combinations of numbers between 2 and 9, on two occasions, 1 week apart.

Table II summarizes the results of these arithmetic fact retrieval tasks.

Despite his severe dysphasia (see Table I), the initial error rates for addition and subtraction tasks were quite low and well within the range of the normal subjects. At the same time, fact retrieval errors were conspicuous in multiplication tasks. Arithmetic fact retrieval declined significantly over the course of 18 months. Errors were usually very close in magnitude to the correct response. The patient appeared to use several back-up procedures to compensate for his less reliable automatic retrieval of arithmetic table facts, such as a counting strategy that often resulted in an underestimate of the correct answer 
TABLE II. Summary of performances (percentages correct) on calculation tasks on two occasions, 18 months apart

\begin{tabular}{lccc}
\hline Task (number of items) & Test & Retest & Control range \\
\hline Arithmetic fact retrieval & & & \\
$\quad$ Addition (larger addendum first) (81) & 95 & 91 & $94-100$ \\
$\quad$ Addition (smaller addendum first) (81) & 99 & 83 & $95-100$ \\
Subtraction (72) & 97 & 75 & $94-100$ \\
Multiplication (128) & 69 & NT & $86-98$ \\
Calculation procedures & & & \\
$\quad$ Divisions (4) & 75 & 75 & $25-100$ \\
Fraction arithmetic (2) & 100 & 50 & $0-100$ \\
Multidigit additions/subtractions (16) & 94 & NT & $81-100$ \\
Complex written additions (20) & 95 & 80 & $90-100$ \\
\hline
\end{tabular}

NT, not tested.

(e.g. " 8 add 2 , that is 8,9 , must be 9"; " 8 add 3 , that is 8,9 , 10 , must be 10 "). Other strategies were multiplying by 2 if the addition consisted of two equal numbers (e.g. " 9 add 9 equals two times 9, equals 18 "), and stepwise solutions (e.g. " 13 add 18 equals 28 and 3, equals 31 "). He often hesitated about his solutions (e.g. $9 \times 6$ : "isn't that 52 ?"; $6 \times 5$ : "might be 31 ?"), or used an algebraic back-up procedure to solve multiplications, like $9 \times 9$ : "that can't be difficult, 10 times 9 equals 90 , minus one (times 9 ) equals 81 "; " 2 times 6 equals 12 , so 3 times 6 must be 18 "; $6 \times 7$ : " 5 times 7 equals 35 , so that is 42 ".

\section{Calculation procedures: fraction arithmetic,} divisions, and complex written additions and subtractions

Both at initial and follow-up testing his results on division and fraction problems (e.g. 72 by $12 ; 18$ minus $71 / 2$ ) were well within the range of normal controls. On 16 written addition and subtraction problems of increasing complexity, including numbers containing zeros such as 60100 minus 4712, and 3306 plus 1704, he wrote the correct solution of seven out of eight additions and all subtractions. His four errors at follow-up testing, to 20 written addition problems to test his knowledge of carrying procedures, derived from Hitch (1978), were straightforwardly interpretable as resulting from his increased fact retrieval impairment. For example, his solution of 314 to $241+63$ was correct in carrying 10 to hundred but incorrect because of an error to $4+6=11$.

On a test of 24 printed dice patterns that he was supposed to count, he spontaneously applied multiplication to count the total number of dots (varying from 12 to 49), though 11 multiplications were incorrect due to fact retrieval errors.

\section{DISCUSSION}

In the context of a severe impairment to the semantic aspects of language, the patient retained the phonological representations of number words and other words in his language (except for irregular words). He was correctly guided by the lexical and syntactical constraints in Arabic number reading. Though he had a selective difficulty in processing written operational signs, he still mastered the computational procedures of addition, subtraction and multiplication, despite impaired retrieval of table facts.

The symptom pattern of this patient thus suggests a distinction between impaired language and retained calculation abilities. Interestingly, a demented patient studied by Grafman et al. (1989) presented with the reverse pattern of initial calculation deficits, procedural errors in multiplication tasks and syntactic errors in reading and writing Arabic numbers, while verbal semantics were spared. These neuropsychological dissociations in demented patients offer strong support for the hypothesis that the spared cognitive system is psychologically distinct and modular in its functioning, i.e. relatively independent from other cognitive systems.

Why should the comprehension of numerical quantities dissociate from the comprehension of words and objects? First, normal cognitive representations of Arabic numbers and numeric operations have a very strong visuospatial component, and may therefore be conceptualized as distinct from verbal-semantic concepts. Second, the semantic information in numbers is about numerical quantities or entities, whereas the semantic information in words refers to the identity of objects (by name or attributes). This psychological distinction is corroborated by developmental studies demonstrating that infants acquire numerical concepts well before they acquire language. Numerical quantities can be handled by a preverbal system (Dehaene and Cohen, 1991; Howard, 1992; Wynn, 1992). Conceptual differences between the two symbolic systems of numbers and words thus offer a psychological explanation for the differential ontogeny and differential vulnerability of these systems to different types of brain dysfunction.

Does this mean that calculation processes and numerical skills are completely separate from language processes? The symptom profile of our patient clearly argues 
against such a strong modularity view, since we found some important continuities between numerical and verbal processing. For example, the dissociation between intact arithmetical procedures and impaired fact retrieval within the mathematical domain was paralleled by a dissociation within the domain of language between intact phonological and syntactic procedures and impaired retrieval of content words.

How should the spared and impaired cognitive systems be characterized in this patient? His difficulties in word retrieval, word comprehension and the progressive loss of arithmetic table facts in a later stage of his illness, all seem to indicate one fundamental cognitive deficit: degradation of the central semantic store of learned factual knowledge. This impairment can be contrasted with his intact rules of grammar and intact procedures of calculation, regulating the combination of lexical elements in the processes of word formation, sentence construction, and number word formation in Arabic number reading. The pattern of deficits and preserved abilities thus suggests a dividing line, within the domains of language and calculation, between impaired semantic and intact procedural knowledge. Such a state of affairs signals the distinction between brain systems concerned with the stored traces that support the operation of semantic memory on the one hand, and the rule-governed processes of language and calculation on the other.

\section{REFERENCES}

Dehaene S and Cohen L (1991) Two mental calculation systems: A case study of severe acalculia with preserved approximation. Neuropsychologia, 29, 1045-1074.
Diesfeldt HFA (1992) Impaired and preserved semantic memory functions in dementia. In: Memory Functioning in Dementia (Ed. L Bäckman), pp. 227-263. Elsevier, Amsterdam.

Freedman L, Selchen DH, Black SE, Kaplan R, Garnett ES and Nahmias C (1991) Posterior cortical dementia with alexia: Neurobehavioral, MRI, and PET findings. Journal of Neurology, Neurosurgery and Neuropsychiatry, 54, 443-448.

Geary DC (1993) Mathematical disabilities: Cognitive, neuropsychological, and genetic components. Psychological Bulletin, 114, 345-362.

Grafman J, Kampen D, Rosenberg J, Salazar A and Boller F (1989) The progressive breakdown of number processing and calculation ability: A case study. Cortex, 25, 121-133.

Hitch GJ (1978) The role of short-term working memory in mental arithmetic. Cognitive Psychology, 10, 302-323.

Hodges JR, Patterson K, Oxbury S and Funnell E (1992) Semantic dementia: Progressive fluent aphasia with temporal lobe atrophy. Brain, 115, 1783-1806.

Howard RW (1992) Classifying types of concept and conceptual structure: Some taxonomies. European Journal of Cognitive Psychology, 4, 81-111.

Macaruso P, Harley W and McCloskey M (1992) Assessment of acquired dyscalculia. In: Cognitive Neuropsychology in Clinical Practice (Ed. DI Margolin), pp. 405-434. Oxford University Press, New York.

McCloskey M, Aliminosa D and Macaruso P (1991) Theorybased assessment of acquired dyscalculia. Brain and Cognition, 17, 285-308.

Neary D, Snowden JS, Northen B and Goulding P (1988) Dementia of the frontal lobe type. Journal of Neurology, Neurosurgery, and Psychiatry, 51, 353-361.

Schwartz MF (1990) Modular Deficits in Alzheimer-type Dementia. MIT Press, Cambridge, MA.

Shallice T (1988) From Neuropsychology to Mental Structure. Cambridge University Press, Cambridge.

Wynn K (1992) Addition and subtraction by human infants. Nature, 358, 749-750.

(Received 17 October 1993; accepted 18 October 1993) 


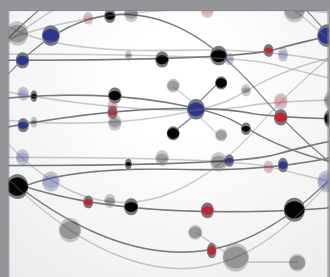

The Scientific World Journal
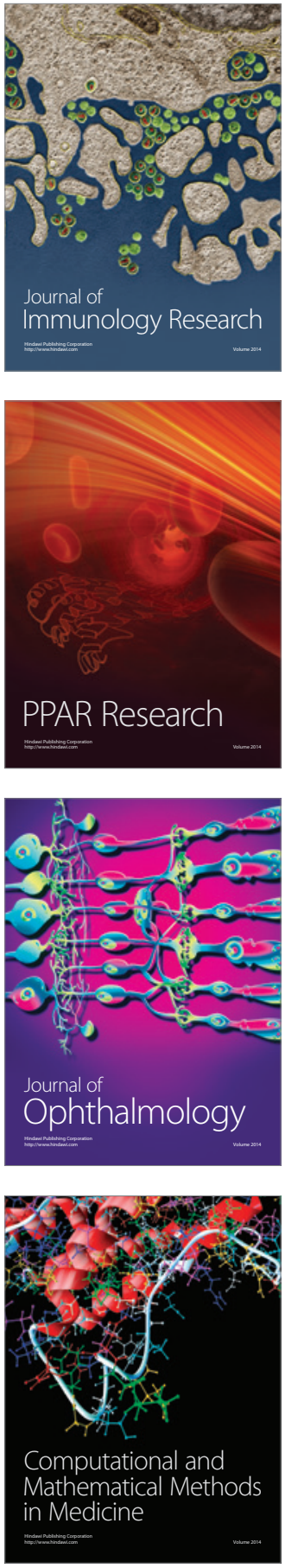

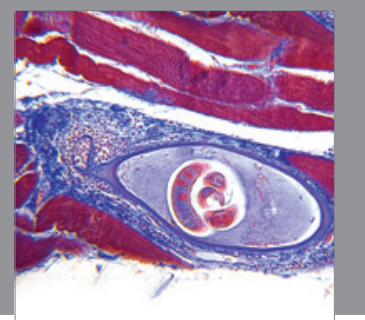

Gastroenterology

Research and Practice
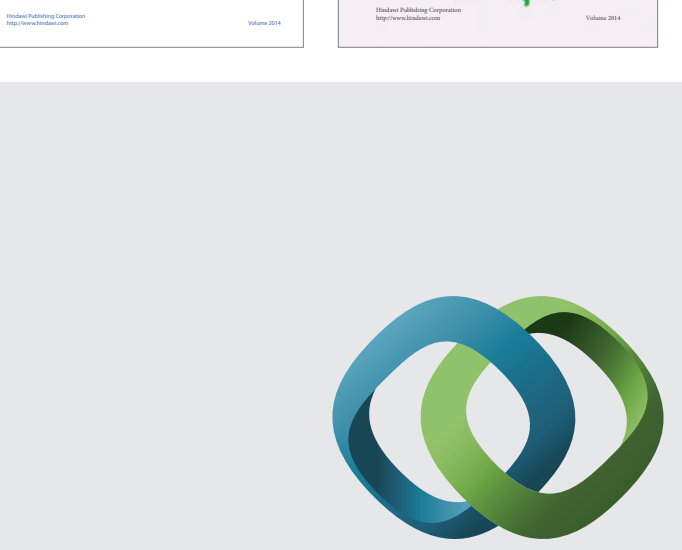

\section{Hindawi}

Submit your manuscripts at

http://www.hindawi.com
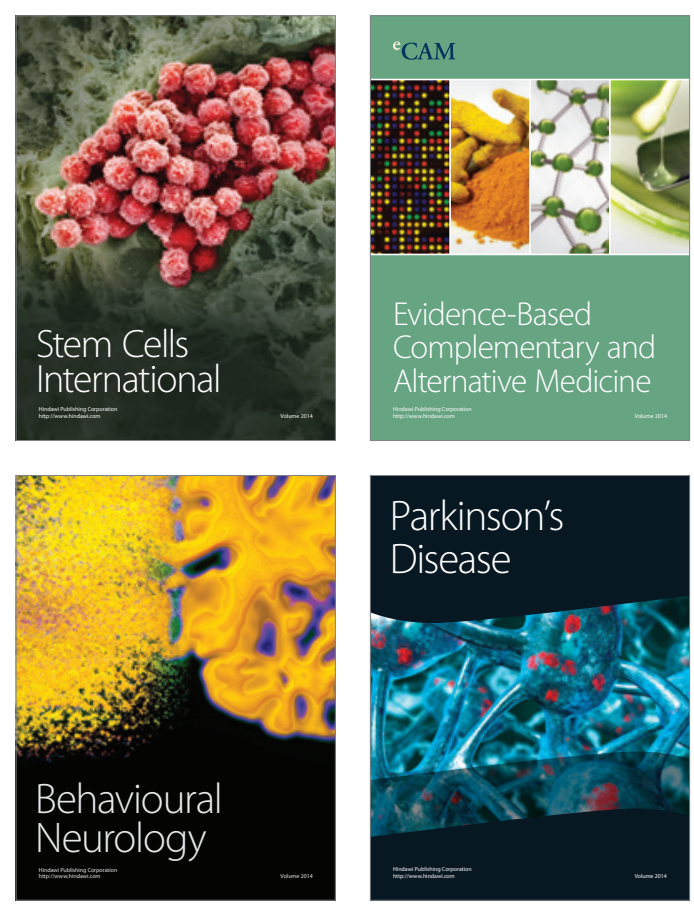

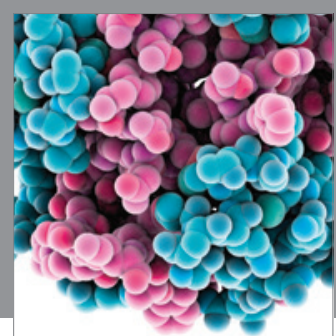

Journal of
Diabetes Research

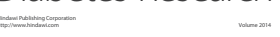

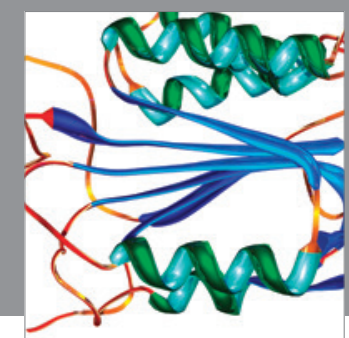

Disease Markers
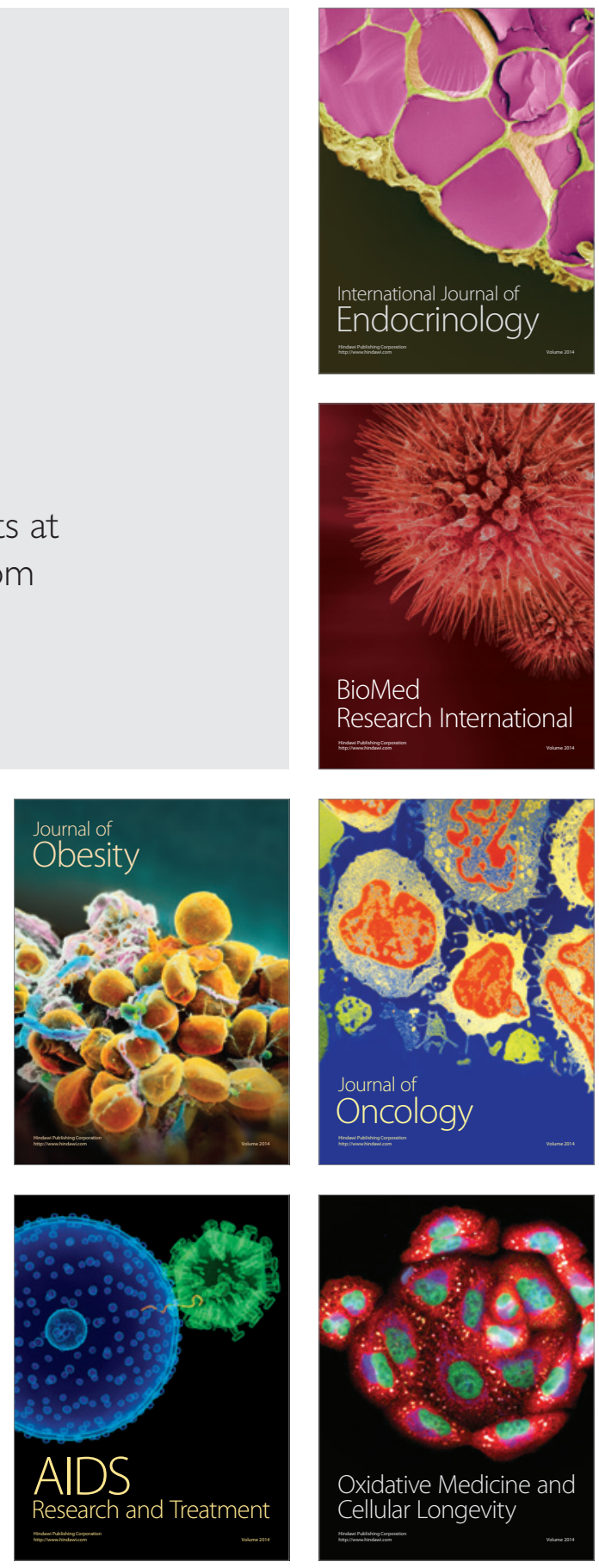